\title{
Study of Surface Roughness of Machined Polymer Composite Material
}

\author{
Zuzana Hutyrová,, ${ }^{1,2}$ Jozef Zajac, ${ }^{1}$ Peter Michalik, ${ }^{1}$ Dušan Mital', \\ Ján Duplák, ${ }^{1}$ and Stanislav Gajdos ${ }^{1}$ \\ ${ }^{1}$ Faculty of Manufacturing Technologies, Technical University of Kosice with Seat in Presov, Sturova 31, 08001 Presov, Slovakia \\ ${ }^{2}$ Nanotechnology Centre, VSB-TUO, 17. Listopadu 15/2172, Poruba, 70833 Ostrava, Czech Republic \\ Correspondence should be addressed to Zuzana Hutyrová; zuzana.hutyrova@tuke.sk
}

Received 5 August 2014; Revised 18 December 2014; Accepted 22 December 2014

Academic Editor: Mahbub Hasan

Copyright ( 2015 Zuzana Hutyrová et al. This is an open access article distributed under the Creative Commons Attribution License, which permits unrestricted use, distribution, and reproduction in any medium, provided the original work is properly cited.

The aim of this paper is to evaluate the influence of selected cutting parameters (speed of rotation and feed rate) on the surface topography of drilled WPC material. Objective of the study is to establish dependence of the surface roughness of borehole walls (parameter $R z$-average maximum height) on the speed of rotation and feed rate of a drill bit. Technological parameters of experimental drilling were feed rate of $100-300 \mathrm{~mm} \cdot \mathrm{min}^{-1}$ and speed of rotation of $2000-6000 \mathrm{rpm}$.

\section{Introduction}

In the field of composite materials reinforced with natural fibers the following ways of machining are preferred.

(i) Milling. Study [1] is one of the first published works, which are focused on wear of milling tools in technology of circumferential milling of commercially acquired WPC materials and comparative samples (classic wood). The author registered higher wear of tools when machining WPCs in comparison to machining of wood. He assumes that the increased wear of tools for machining WPCs was due to their composition and modified properties. Type of a matrix used in the production of composites represents an important factor affecting the quality of machined surfaces.

(ii) Cutting. The publication [2] describes the relationship between the speed of cutting when sawing and the quality of machined surfaces of three samples of WPCs with a different matrix (PE/PP/PVC) + rice hull flour. The experimental results show that the spindle speed has a significant effect on the surface quality of the machined samples. The advantage of using a high cutting speed in sawing WPCs is evident. (iii) Turning. The publications $[3,4]$ describe the quality of machined surfaces after turning with a monolithic HSS tool when changing the feed rate of machining (at a constant cutting speed and depth of cut). It is recommended to use the tools with a large radius of curvature and lower feed rates.

(iv) Drilling. In recent years there have been a large number of studies focused on evaluation of the effects that input cutting parameters have on achieved quality of holes. Study [5] assessed the quality of boreholes in composite material with $\mathrm{PE}$ matrix and hemp fiber reinforcement (density of $1350 \mathrm{~kg} \cdot \mathrm{m}^{-3}$ and module of $3.25 \mathrm{GPa}$, prepared with a use of hand lay-up process). The authors recommend the use of higher cutting speeds and lower values of feeds for achieving minimal damage to the holes (regarding maintaining the roundness of the holes).

In [6] the so-called "green" materials are machined (composites reinforced by bamboo and Japanese cedar fibers). The thrust force (its effect on quality of the holes), chip forming, and tool wear are evaluated in this study.

Based on analysis of present state of the problematic and study of research and scientific publications, it can be stated 
TABLE 1: Mechanical properties of tested material (tensile strength test).

\begin{tabular}{lccc}
\hline $\begin{array}{l}\text { Number } \\
\text { of } \\
\text { samples }\end{array}$ & $\begin{array}{c}\text { Ultimate tensile } \\
\text { strength [Mpa] }\end{array}$ & $\begin{array}{c}\text { Relative elongation } \\
{[\%]}\end{array}$ & $\begin{array}{c}\text { Reduction } \\
{[\%]}\end{array}$ \\
\hline 1 & 24 & 2.8 & 2.0 \\
2 & 15 & 2.9 & 0.4 \\
3 & 24 & 3.4 & 0.8 \\
4 & 15 & 5.1 & 0.4 \\
5 & & Defect & \\
\hline
\end{tabular}

TABLE 2: Mechanical properties of tested material (three-point bending test).

\begin{tabular}{lc}
\hline Number of samples & Ultimate bending strength [Mpa] \\
\hline 1 & 18.76 \\
2 & 15.69 \\
3 & 16.71 \\
4 & 15.44 \\
5 & 17.13 \\
\hline
\end{tabular}

that nowadays there are no available quality and relevant scientific outputs from the area of monitoring the topography of machined wood plastic composites. In the light of this, this paper is presented focusing on experimental study of surface topography after machining-drilling at exactly designed experimental conditions (technological parameters such as feed rate and spindle speed, which are regarded in whole experiment as variable and other influences on the experiment are considered as constant because experiment was carried out at the same conditions and with the same tools, machines, and devices).

\section{Materials and Methods}

In the experiment samples of natural fiber reinforced composite were used. The material consists of HDPE matrix reinforced with wood fibers or chips (more than $75 \%$ vol.). Machined profile (with dimensions of $60 \times 40 \times 3600 \mathrm{~mm}$ ) was manufactured by extrusion technology. Mechanical properties of the composite are given in Tables 1 and 2. The ultimate tensile strength (Table 1) was determined according to ISO 6892-1, with a constant load speed of $0.015 \mathrm{~mm} \cdot \mathrm{s}^{-1}$. The ultimate bending strength was determined using the threepoint bending test (Table 2) according to ISO 178-1, with a constant load speed of $0.08 \mathrm{~mm} \cdot \mathrm{s}^{-1}$. The test samples were cut out from the middle part of the profile in direction parallel to the axis of extrusion. A microscopic image of the material structure before machining is shown in Figure 1. The material contains microcracks mostly localized in the contact area of wood and plastic. The length of microcracks ranges from $20 \mu \mathrm{m}$ to $4 \mathrm{~mm}$. Some cracks pass even through the wood chips in the direction of their longitudinal axis. Cracks are unevenly distributed throughout the volume of the material. Orientation of wood particles follows the flow of the polymer.

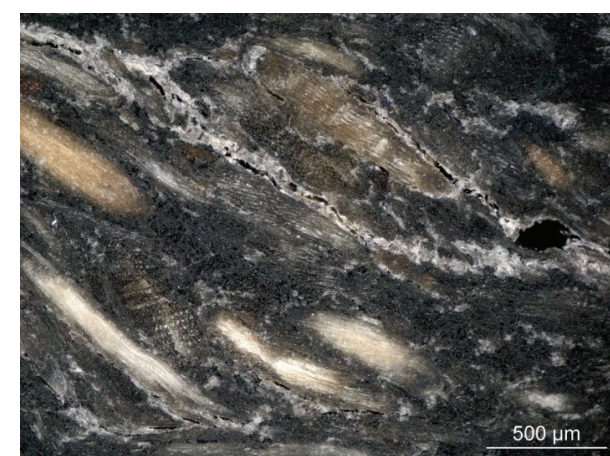

FIGURE 1: Microscopic structure of the tested WPC material (optical microscope Nikon Eclise 80i, reflected light).

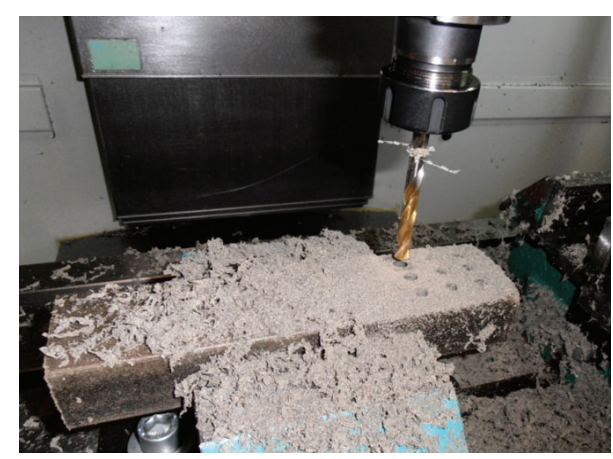

Figure 2: Holes with required diameter drilled into the material.

Two types of drill bits made of high-speed steel (HSS) without any unusual additives of alloy components (DIN 338) were used for drilling of tested samples:

(i) drill bit number 1-with TiN coating;

(ii) drill bit number 2-without coating, with surface finish-blackening.

The drill bits had the same diameter of $9.0 \mathrm{~mm}$, working length of $l_{t}=125 \mathrm{~mm}$, apical angle of the point of $\varepsilon_{r}=118^{\circ}$, and helix angle of $\lambda=30^{\circ}$.

The three-axis vertical machining centre Pinnacle VMC650S was used as a working machine. The frame saw ERGONOMIC 275.230 DG was used to cut samples with required dimensions of $230 \mathrm{~mm}$. The process of cutting and drilling was realized without using process fluids (drilled holes-passable, deep drill strategy). Technological parameters of the cutting process are shown in Table 3.

\section{Results and Discussion}

For each configuration of the drilling system, three boreholes were made (Figure 2). To measure the parameter of surface roughness the MITUTOYO SJ-400 device was used with contact operation with the automatic compensation of radius and inclination, with an evaluation length of $l_{r}=4.0 \mathrm{~mm}$ (filter profile $\lambda_{c}=2.5 \mathrm{~mm}$ ). Before the measurement, the samples were cut in the axis parallel to holes (Figure 3). The surface roughness was measured at the distance of 
TABLE 3: Technological parameters of the cutting process and marking of holes.

\begin{tabular}{|c|c|c|c|c|c|c|c|c|c|}
\hline Hole number & 1 & 2 & 3 & 4 & 5 & 6 & 7 & 8 & 9 \\
\hline Spindle speed [rpm] & 2000 & 4000 & 6000 & 2000 & 4000 & 6000 & 2000 & 4000 & 6000 \\
\hline Feed rate $\left[\mathrm{mm} \cdot \mathrm{min}^{-1}\right]$ & 100 & 100 & 100 & 200 & 200 & 200 & 300 & 300 & 300 \\
\hline
\end{tabular}

TABLE 4: Dependence equations $R z$ on changing conditions of the cutting process (the first equation is for the HSS tool with TiN coatingwith $*$; the second equation is for the HSS tool without coating).

\begin{tabular}{|c|c|c|c|}
\hline & Dependence equations $R z=f(f)$ & & Dependence equations $R z=f(n)$ \\
\hline \multirow{2}{*}{$f=100 \mathrm{~mm} \cdot \mathrm{min}^{-1}$} & $R z=5.6667 f+5.5139 R^{2}=0.8824^{*}$ & \multirow{2}{*}{$n=2000 \mathrm{rpm}$} & $R z=2.6875 n+11.153 R^{2}=0.5286^{*}$ \\
\hline & $R z=10.508 f+0.8111 R^{2}=0.9116$ & & $R z=4.9917 n+7.7222 R^{2}=0.9714$ \\
\hline \multirow{2}{*}{$f=200 \mathrm{~mm} \cdot \mathrm{min}^{-1}$} & $R z=1.7375 f+16.267 R^{2}=0.3224^{*}$ & \multirow{2}{*}{$n=4000 \mathrm{rpm}$} & $R z=5.6708 n+7.6889 R^{2}=0.8988^{*}$ \\
\hline & $R z=8.7875 f+4.6972 R^{2}=0.7113$ & & $R z=-0.5458 n+18.031 R^{2}=0.2371$ \\
\hline \multirow{2}{*}{$f=300 \mathrm{~mm} \cdot \mathrm{min}^{-1}$} & $R z=3.0375 f+16.383 R^{2}=0.7113^{*}$ & \multirow{2}{*}{$n=6000 \mathrm{rpm}$} & $R z=0.0583 n+23.372 R^{2}=0.0145^{*}$ \\
\hline & $R z=-1.725 f+23.414 R^{2}=0.3052$ & & $R z=-7.2417 n+43.903 R^{2}=0.7465$ \\
\hline
\end{tabular}

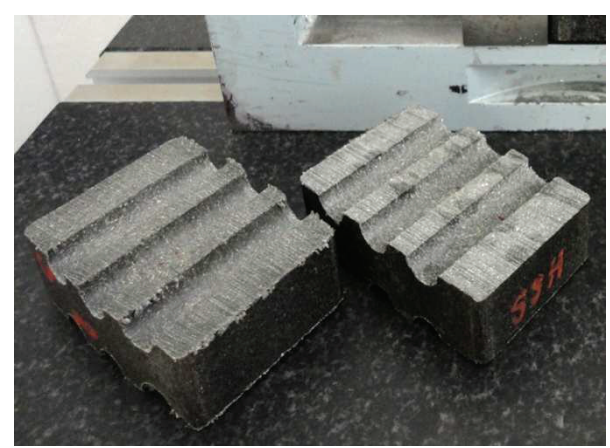

FIGURE 3: Sample before surface roughnesss measurement (inner hole and marginal hole).

$20 \mathrm{~mm}$ from the beginning of the hole on the right and left sides, with repeating 3 times. The values used in graphs in Figures 4 and 5 represent arithmetic averages of 3 measurements of the right and left sides of marginal and inner holes.

The following is description of graphic representations and linear dependence equations.

(i) HSS Drill Bit with TiN Coating (Tool 1). At the constant feed rate of $f=100 \mathrm{~mm} \cdot \mathrm{min}^{-1}$ the values of $R z$ parameter rise with increasing revolution. At the feed rate of $f=200 \mathrm{~mm} \cdot \mathrm{min}^{-1}$ the $R z$ values decrease at $n=4000 \mathrm{rpm}$ and then they subsequently go up (by $6.1 \mathrm{~mm}$ ). At the maximum feed rate of $300 \mathrm{~mm} \cdot \mathrm{min}^{-1}$ the values of $R z$ parameter act oppositely to the previous case (Figure 4(a)). Based on linear dependency equations the increasing tendency is visible in case of all three feed rates (Table 4, highlighted lines). However, the coefficient of determination is not greater than 0.90 in any of the cases and therefore the equations are not statistically important. Figure 4(b) shows the graphic dependence of $R z$ on increasing feed rate. At the minimal revolution the $R z$ values increase at the feed rate of $200 \mathrm{~mm} \cdot \mathrm{min}^{-1}$ and then they subsequently decrease under $1.7 \mu \mathrm{m}$. At the revolution of $4000 \mathrm{rpm}$ there is an evident increase of $R z$ values in the whole range of feed rates. At the maximum revolution the course is almost constant even at the change of the feed rate. Linear equations confirm these courses, but when the statistical significance is concerned, however, none meets the criterion $R^{2}>0.90$.

(ii) HSS Drill Bit without Coating (Tool 2). The $R z$ values rise with increasing revolution at the feed rates of 100 and $200 \mathrm{~mm} \cdot \mathrm{min}^{-1}$. A significant increase is visible when the revolution is changed from $4000 \mathrm{rpm}$ to $6000 \mathrm{rpm}$. Maximum reached values are almost identical (at $n=4000 \mathrm{rpm} \rightarrow R z_{\max }=34.225 \mu \mathrm{m}$; at $\left.n=6000 \mathrm{rpm} \rightarrow R z_{\max }=34.292 \mu \mathrm{m}\right)$. At the maximum feed rate of $300 \mathrm{~mm} \cdot \mathrm{min}^{-1}$ the $R z$ value decreases and then subsequently increases at the maximum revolution of $6000 \mathrm{rpm}$ (Figure 5(a)). Linear dependence equations show evident increasing course, but only the dependence of $R z$ on the revolution at the minimum feed rate of $100 \mathrm{~mm} \cdot \mathrm{min}^{-1}\left(R^{2}=0.9116\right)$ is statistically significant. Figure 5(b) shows the visible change in course of $R z$ depending on increasing feed rate. At the minimum revolution the values of $R z$ parameter rise with the increasing feed rate. The opposite course is evident at maximum revolution. At the revolution of $4000 \mathrm{rpm}$ the values range in a narrow intervalfrom less than $17 \mu \mathrm{m}$ up to $18.05 \mu \mathrm{m}$. Statistically important is the course at the revolution of $2000 \mathrm{rpm}$. Coefficient of determination is greater than 0.97. In case of higher revolution the equations are statistically insignificant and they have a decreasing tendency.

(iii) Graphic dependencies differ depending on the use of tools with the same diameters but different surface finish (tools with/without coating). Using the tool with TiN coating the better quality of the surface (lower values of $R z$ parameter) was achieved. Use of a drill bit with surface finish improves the quality of the surface by more than $20 \%$. On the other side, the differences in obtained values are minimal at the feed 


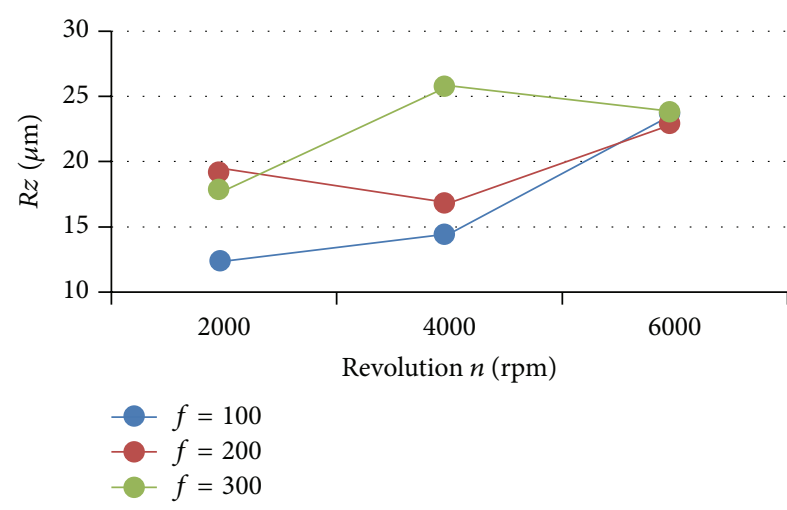

(a) Tool 1: HSS + TiN

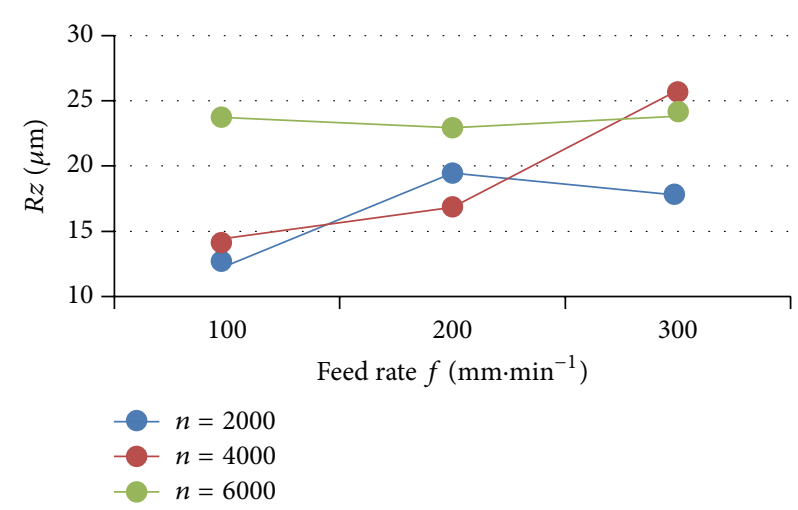

(b) Tool 1: HSS + TiN

FiguRE 4: (a) Dependence of surface roughness parameter $R z$ on revolution; (b) dependence of surface roughness parameter $R z$ on feed rate (HSS tool with TiN coating).

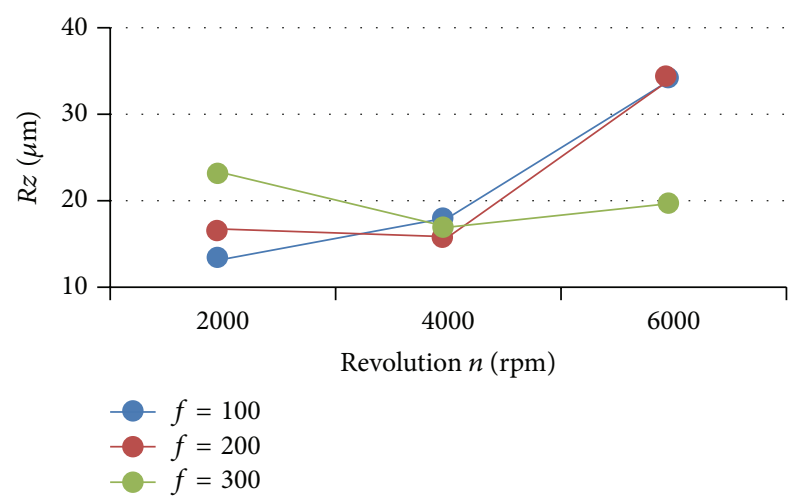

(a) Tool 2: HSS

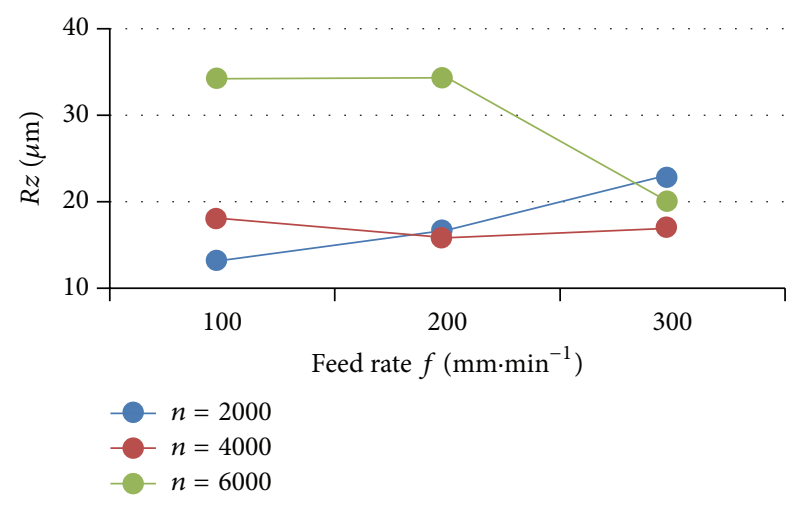

(b) Tool 2: HSS

FIGURE 5: (a) Dependence of surface roughness parameter $R z$ on revolution; (b) depedence of surface roughness parameter $R z$ on feed rate (HSS tool without coating).

rate of 100 and $200 \mathrm{~mm} \cdot \mathrm{min}^{-1}$ and at the minimal revolution.

Figures 6(a)-6(f) show the images obtained using a digital camera. Chips were removed from the place of a cut by a grove in the tool. Some melting of plastic and its sticking to the adjacent back part of a drill bit occurred during the process of cutting. In the case of coated tool the sticking of material matrix was even more apparent. When using a tool without coating the sticking of polymer does not occur in such extent. With regard to heterogeneity of the material it is not possible to categorize the formed chips into groups in more detail; the particular section of chips has different shapes (alongside the inner volume there is a different ratio of plastic and wood and the wooden parts are of different sizes). The edge of a hole is without damage in the part where a drill bit enters the material. In the area where a drill bit exits the material deformation occurs and a part of chip is fixed to the edge of a hole (see Figures 6(e) and 6(f)).

It is necessary to note that experimental results are valid only for presented technological conditions and tools, so in the future it is recommended to study other tools and technological parameters of machining and also to determine the most suitable conditions to achieve surface with highest quality.

\section{Conclusion}

Topography of the surface is prescribed by interaction between tool and machined material and its properties. Along the extruded profile the mechanical properties of the studied material are different, which was proved by mechanical testing. The microscopic observation of the material structure showed the heterogeneity of the composite and also presence of microcracks located on contacts between wood particles and the polymer matrix. Graphical dependencies of studied parameters were constructed using values calculated as arithmetic average of $R z$ values measured on the surface of inner and marginal bore holes, which in the light of inhomogeneity of material are correlation coefficients at low values, which show statistical significance of described dependencies $R z=$ $f(f)$ and $R z=f(n)$, respectively. In relation to changing characteristic along the profile it is not able to predict course of roughness parameters for variable parameters (depending on conditions of cutting process). Inhomogeneity can be 


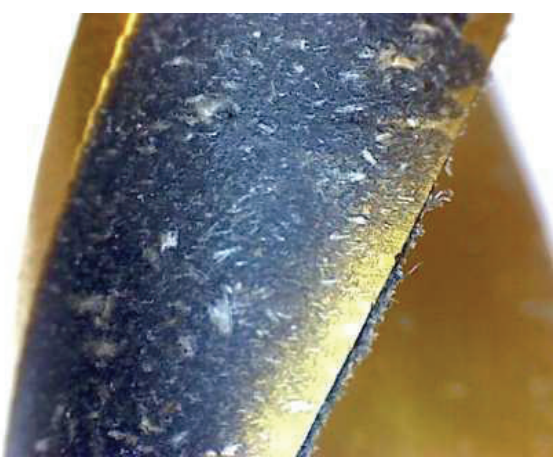

(a)

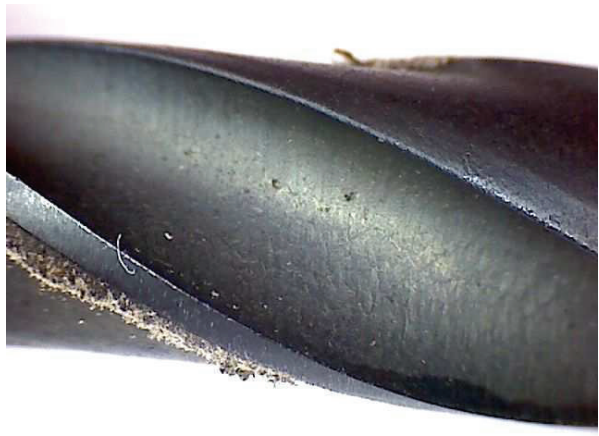

(c)

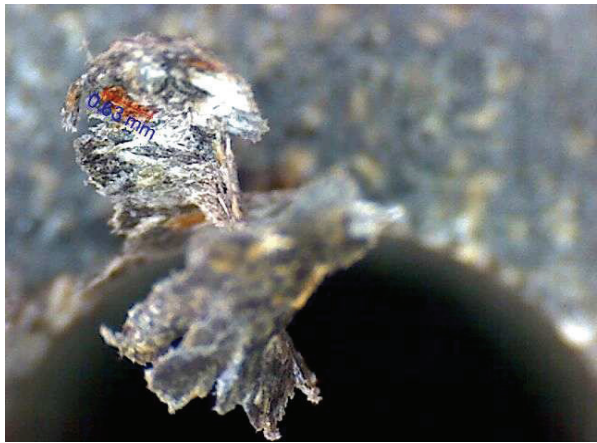

(e)

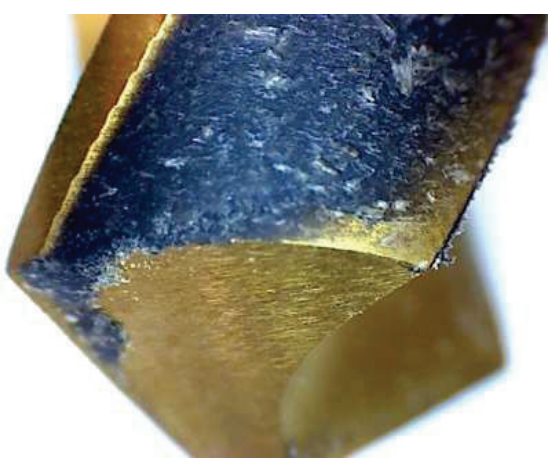

(b)

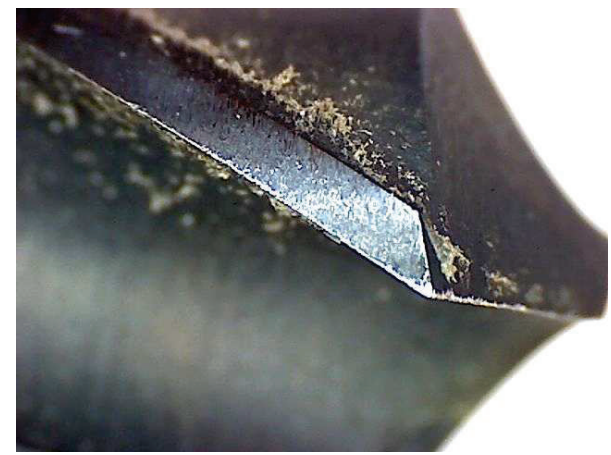

(d)

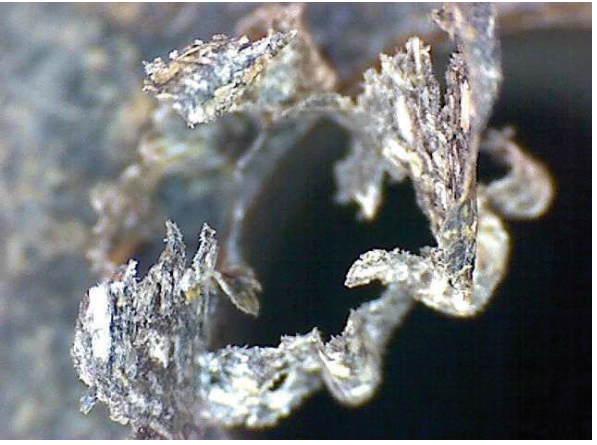

(f)

Figure 6: Macroscopic images obtained using a digital microscopic camera Digi Micro 2.0: (a) and (b) details of tool with TiN coating after drilling, (c) and (d) details of tool without coating after drilling, and (e) and (f) details of bored hole.

partially reduced by adding of coupling substance in production process of profile (reduction of cracks on borders wood-plastics). Further research can be possible pointed on material area-exactly to increase homogeneity of material.

\section{Conflict of Interests}

The authors declare that there is no conflict of interests regarding the publication of this paper.

\section{Acknowledgments}

This research was done in the framework of the Project New Creative Teams in Priorities of Scientific Research (registration no. CZ.1.07/2.3.00/30.0055), supported by Operational
Programme Education for Competitiveness and cofinanced by the European Social Fund and state budget of the Czech Republic.

\section{References}

[1] D. Saloni, U. Buehlmann, and R. L. Lemaster, "Tool wear when cutting wood fiber-plastic composite materials," Forest Products Journal, vol. 61, no. 2, pp. 149-154, 2011.

[2] X. L. Guo, N. H. Liu, W. Gao, P. X. Cao, and Y. Guo, "Effects of spindle speed on surface qualities in WPC sawing," Applied Mechanics and Materials, vol. 33, pp. 487-491, 2010.

[3] Z. Šomšáková, J. Zajac, P. Michalik, and M. Kasina, "Machining of wood plastic composite (pilot experiment)," Materiale Plastice, vol. 49, no. 1, pp. 55-57, 2012. 
[4] Z. Hutyrová, M. Harničarová, J. Zajac, J. Valíček, and J. Mihok, "Experimental study of surface roughness of wood plastic composites after turning," Advanced Materials Research, vol. 856, pp. 108-112, 2013.

[5] D. Babu, K. S. Babu, and B. U. M. Gowd, "Drilling uni-directional fiber-reinforced plastics manufactured by hand lay-up influence of fibers," American Journal of Materials Science and Technology, vol. 1, pp. 1-10, 2012.

[6] A. Mizobuchi, H. Takagi, T. Sato, and J. Hino, "Drilling machinability of resin-less green composites reinforced by bamboo fiber," in Proceedings of the 4th International Conference on High Performance Structures and Materials (HPSM '08), pp. 185-194, May 2008. 

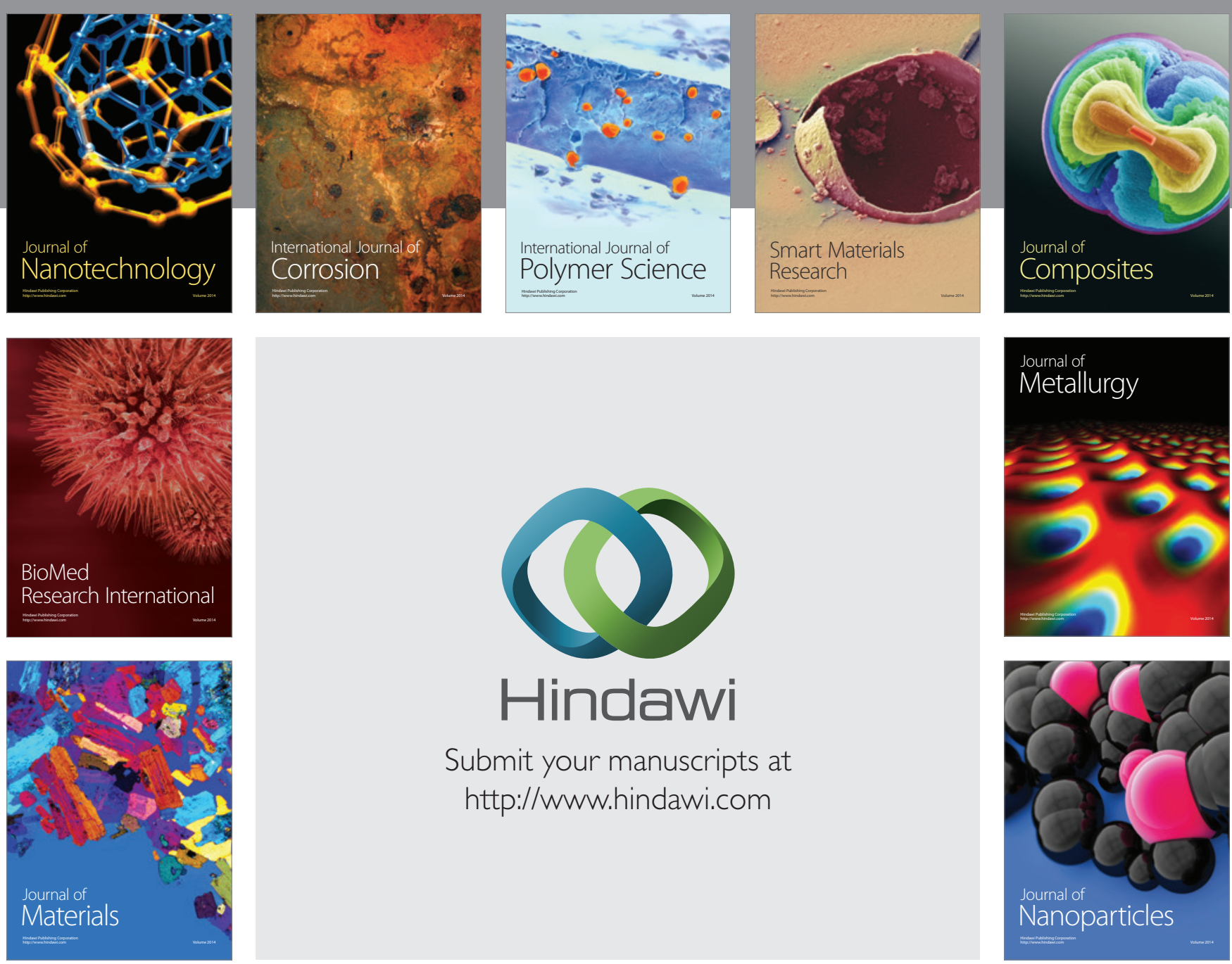

Submit your manuscripts at http://www.hindawi.com
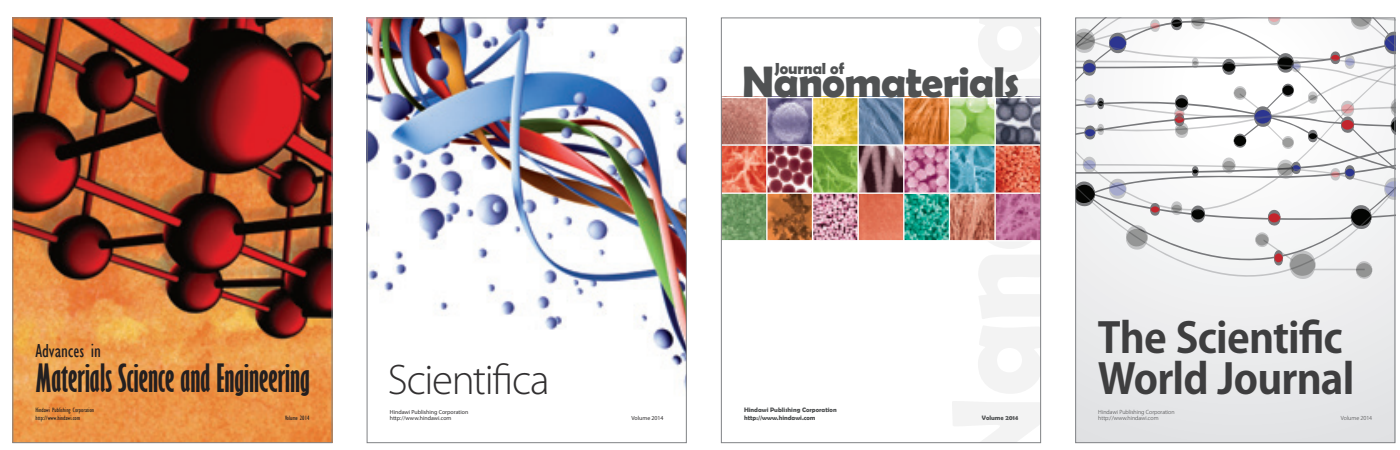

\section{The Scientific World Journal}
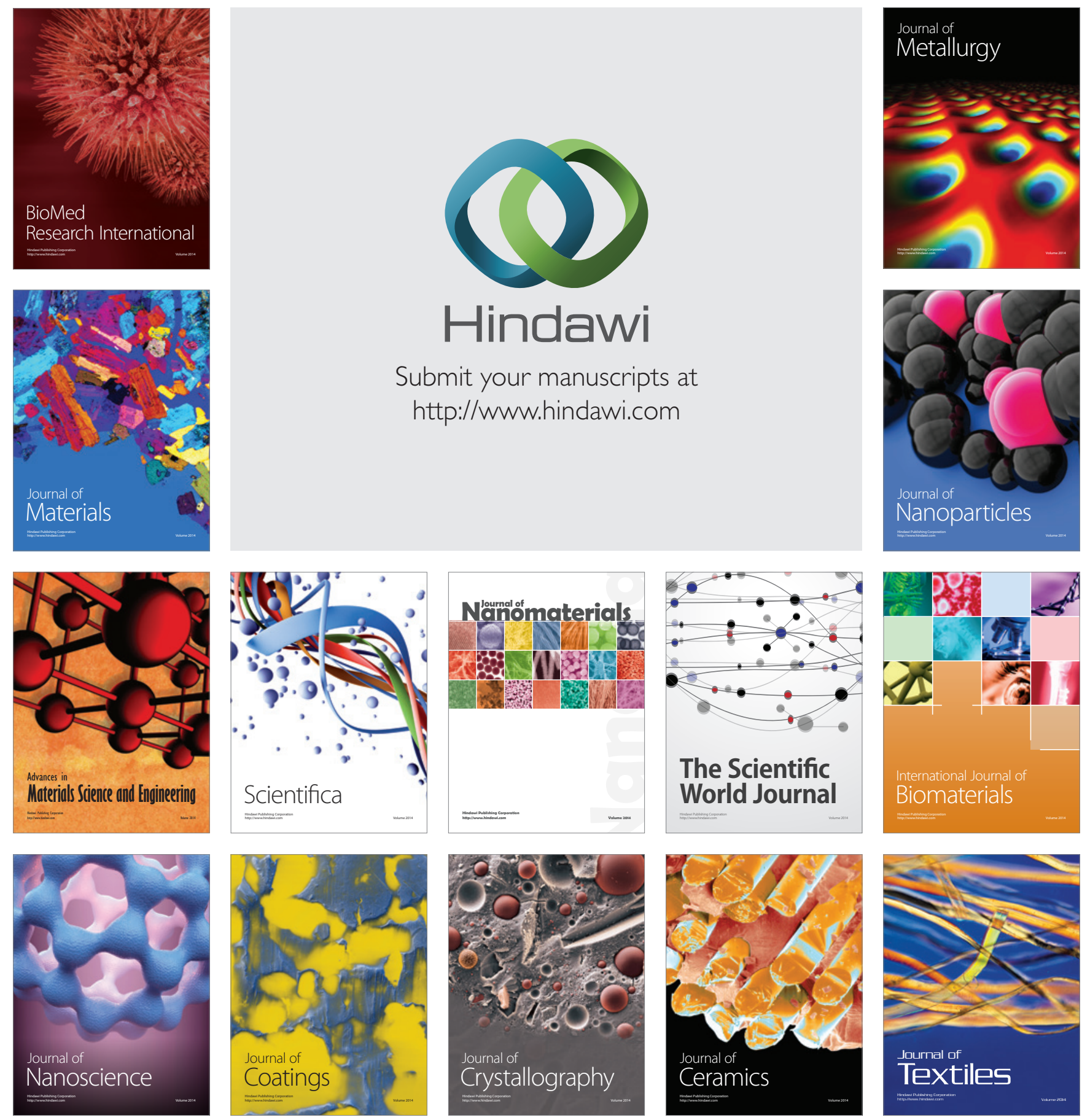